\title{
Experiments with Externally Prestressed Continuous Composite Girders
}

\author{
M. Safan, A. Kohoutková
}

Steel-concrete composite girders have attractive potentials when applied in bridge construction. The serviceability performance of continuous composite girders is becoming more and more a deterministic parameter in the design of this type of structures. An effective method for improving this performance is to apply prestressing to control or completely eliminate concrete deck cracking caused by static and time dependent actions. Little literature has been found addressing the experimental analysis of continuous girders prestressed by means of external deviated tendons. The current research aims to investigate the behavior of a double-span steel composite beam externally prestressed by means of continuous tendons in terms of cracking characteristics, load deflection response, and load carrying capacity. The efficiency of prestressing is evaluated by comparing the results to those of a non-prestressed beam with similar cross sections and spans.

Keywords: composite steel-concrete beams, serviceability, external prestressing, deviated tendons.

\section{Introduction}

Steel-concrete composite beams are an attractive form of construction in both buildings and bridges due to economic and efficiency considerations. In a typical composite beam section, a reinforced concrete slab is connected to the top flange of a steel beam, providing a stronger and stiffer carrying element. In the case of continuous composite beams, the concrete slab is most effective in positive bending, forming a wide compressive flange and raising the position of the neutral axis so that most of the steel section is available to carry tension. In negative bending, the slab, being subjected to tensile stresses, is less far beneficial due to possible cracking under service load conditions. Such cracking considerably reduces the contribution of the slab to the strength and stiffness of the beam. In the case of bridges, cracking and possible subsequent deterioration of the concrete slab and corrosion of the rebars due to weathering effects may lead to a serviceability failure. Prestressing can be used effectively to control or to completely eliminate deck cracking in composite beams. Prestressing action can be induced by means of internal tendons running through the slab or externally by means of continuous deviated or discontinuous straight tendons connected to the steel structure. The present work investigates the contribution of external unbonded deviated tendons to improving the performance in terms of cracking characteristics and load-deflection response up to the ultimate capacity of the beam section at the inner support. An experimental program was conducted to test two identical double-span beams that were made as a composite of a reinforced concrete slab $(6 \times 60 \mathrm{~cm})$ connected to an I-beam (No. 30) by means of a sufficient number of headed studs so as to attain a rigid connection. Each beam was symmetrical about the inner support, with a total length of $14 \mathrm{~m}$. While the first beam was non-prestressed, the second was prestressed by means of two continuous tendons running close and parallel to the beam web sides. Each tendon was deviated by means of three saddle supports, two at each mid-span section and one at the interior support section. Prestressing was applied at 28 days-age of the concrete slab to ensure the development of adequate compressive strength. The experimental work demonstrated that external prestressing is relatively easy to apply provided that proper dimensional details are designed. Test results indicated that the application of prestressing remarkably improved the mechanical performance in terms of both yield and ultimate loads, and also cracking characteristics needed to ensure better durability performance under service conditions.

\section{Construction alternatives and analysis}

Beside the well established advantages of prestressing, external prestressing offers the advantages of ease of monitoring and modifying the tendon force, ease of replacing the tendons in case of being damaged, and it also offers the possibility of controlling the tendon path. Controlling the tendon path offers the twofold advantage of: (a) inducing the most favourable stress state counteracting the action of the external load depending on the load configuration and (b) controlling the secondary effects resulting from prestressing a continuous beam, which may reduce the load carrying capacity by introducing negative moments at the inner support(s). Prestressing can be applied by various means and following different prestressing sequences. The stresses developing in the different elements of a composite beam may change significantly depending on the construction sequence. Different construction sequences can be described based on possible combinations of the following alternatives: (a) prestressing can be applied through the steel structure and/or the concrete slab, (b) prestressing can be applied to the whole composite structure or to an individual element(s) before the composite action takes place, (c) shoring the steel structure by means of temporary supports removed as soon as the composite action takes place, and (d) concrete casting sequence. Dall'Asta and Dezi [1] made an analytical study of different construction schemes of double-span beams prestressed by external deviated tendons, and concluded that it was more convenient, in terms of crack prevention, to apply prestressing to the composite structure rather than to the sole supporting steel structure. Shoring the steel beam can be applied to further enhance the performance as a result of reduced deflection at all stages of loading. However, Viest et al. [2] demonstrated that shored composite beam construct- 
ion usually cannot be justified from the standpoint of either economy or practical execution.

According to current design codes [3], [4], the design of individual sections for flexural strength is relatively straightforward in terms of plastification and buckling criteria. However the design for serviceability is not as straightforward, considering: (a) the time-dependent effects due to creep and shrinkage inducing excessive deflections associated with moment redistribution along the spans and stress migration within individual sections with expected extension of cracking, (b) additional non-linearity due to cracking [4]. Accordingly, accurate evaluation of prestressing efficiency should extend in time. Studying different prestressing systems in double-span beams, Dezi and Leoni [5] demonstrated that external prestressing by means of deviated tendons produces a more favourable long-term stress state with the possibility of controlling the secondary effects by opportunely choosing the tendon path. This study also showed that it is possible to introduce relaxation losses as an instantaneous effect and to further assume that the prestressing force is constant in time (i.e., neglecting the variation under static, creep, and shrinkage actions). Based on these simplifying assumptions, the prestressing force along the tendon can be introduced as concentrated forces acting at saddle points and anchorages. Complete short and long term analysis can then be conducted using finite element models such as those presented in [6], [7] taking into account the flexibility of the shear connection or a more simplified finite element approach assuming rigid connection and combining the stiffness and flexibility methods to model the beam and the tendon sliding freely at saddle points [8].

\section{Research significance}

The literature addressing prestressing of composite beams showed that more attention has been devoted to the study of internally prestressed continuous beams, while those prestressed by external continuous tendons have received less attention, specially as regards experimental testing. For this reason, it is believed that extensive research work is still needed in this area to explore the behavior for both ultimate and serviceability limit states, and to provide experimental data to investigate the efficiency of the theoretical models proposed for analysis.

\section{Experimental work}

The aim of the experimental work carried out in this research is to investigate the contribution of external prestressing to improving the performance of continuous composite beams. A double-span beam with a $7 \mathrm{~m}$ span length (Beam B) has been prestressed by means of unbonded deviated tendons. Its mechanical performance has been compared to that of a similar, but nonprestressed beam (Beam A) in terms of the following parameters:

1. Cracking characteristics: in terms of cracking load, crack width, number of cracks, and extension of cracks at different loading stages.

2. The efficiency of the slab reinforcement for controlling deck cracking in Beam A.

3. Load-deflection response.

4. Load carrying capacity of the beam in terms of the load carrying capacity of the section at the interior support.

\subsection{Prestressing tendons}

One beam was stressed by means of two single strand tendons produced and installed by VSL Systems - Prague. The $15.5 \mathrm{~mm}$ diameter strand consisted of 7 wires plaited in helical twist configuration. The central wire had a diameter of $5.5 \mathrm{~mm}$ while each of the outer wires had a diameter of $5 \mathrm{~mm}$, yielding a gross tendon area of $141.47 \mathrm{~mm}^{2}$. The following properties were reported by the manufacturer concerning tendon force losses:

1. Maximum intrinsic relaxation $=2.5 \%$ (after 1000 hours at $20{ }^{\circ} \mathrm{C}$ and an initial stress of $70 \%$ of the nominal tensile strength) satisfying the requirements for low relaxation tendons according to ASTM A 416-85.

2. Considering the special procedure developed by the manufacturer for locking the wedges, a loss due to wedge draw-in of approximately $6 \mathrm{~mm}$ occurs upon lock off.

Table 1: $15 \mathrm{~mm}$ - strand properties provided by VSL and specification limits

\begin{tabular}{|l|c|c|c|}
\hline \multirow{2}{*}{\multicolumn{1}{|c|}{ Properties }} & \multirow{2}{*}{$\begin{array}{c}\text { According to } \\
\text { VSL }\end{array}$} & & \multicolumn{2}{c|}{ Limits of specifications } \\
\cline { 3 - 4 } & & $\begin{array}{c}\text { Euronorm 138-79 \& } \\
\text { BS 5896-80 (SUPER) }\end{array}$ & $\begin{array}{c}\text { ASTM A 416-85 } \\
\text { (GRADE 270) }\end{array}$ \\
\hline Nominal Diameter [mm] & 15.50 & 15.7 & 15.2 \\
\hline Nominal Area [mm] & 141.57 & 150 & 140 \\
\hline Nominal Mass $[\mathrm{kg} / \mathrm{m}]$ & 1.11 & 1.18 & 1.10 \\
\hline Yield Stress $[\mathrm{MPa}]$ & 1673.00 & $1500^{(1)}$ & $1670^{(2)}$ \\
\hline Tensile Strength $[\mathrm{MPa}]$ & 1894.00 & 1770 & 260.7 \\
\hline Min. Breaking Load $[\mathrm{KN}]$ & 268.10 & 265.0 & 1950 \\
\hline Young's Modulus $[\mathrm{GPa}]$ & 194.54 & \multicolumn{2}{|c|}{ max. 2.5 } \\
\hline Intrinsic Relaxation $[\%]$ & $(3)$ & & \\
\hline
\end{tabular}

(1) Measured at $0.1 \%$ residual strain $(0.1 \%$ offset method).

(2) Measured at $1.0 \%$ extension ( $1 \%$ extension under load method).

(3) Valid for relaxation class 2 according to Euronorm 138-19 \& BS 5896-80 or low relaxation grade according to ASTM A 416-85. 
Other losses due to friction at saddle points can be neglected without significant loss of accuracy, and thus the tendon force is assumed to be constant along the whole tendon length. Other mechanical characteristics of the prestressing strand are presented in Tab. 1 as provided by the manufacturer. A jacking force of $212 \mathrm{KN} /$ strand was applied so as to induce a jacking stress of $1497 \mathrm{MPa}$ corresponding to the maximum allowable stress of $0.9 f_{y(0.1)}$ as recommended in Eurocode 4 [9], where $f_{y(0.1)}$ is the yield stress measured at $0.1 \%$ residual strain.

\subsection{Fabrication and erection of test beams}

The steel beam with prestressing and bearing assemblies and welded shear connectors was fabricated at the Metrostav Company workshops - Prague. The steel structure was erected in its final position for testing at the Prague State Technical Laboratories, where casting of the concrete slab was performed by Metrostav and prestressing by VSL Systems Corporation in Prague.
The steel beam (rolled I-beam No. 30, grade 37) was fabricated and delivered to the laboratory in one piece and supported in the final position. The steel beam had a total length of $14.2 \mathrm{~m}$, allowing $10 \mathrm{~cm}$ of the beam length to extend beyond the end supports, Fig. 1. The prestressing force was transferred to the composite beam through a thick steel end plate $(140 \times 110 \times 15 \mathrm{~mm})$ welded to the steel beam, Fig. 2. Each prestressing tendon was deviated by means of three saddle points; two at each mid-span section and one at the intermediate support. For this purpose, the tendon was guided at these locations by means of curved steel tubes (24 $\mathrm{mm}$ inner diameter and $4 \mathrm{~mm}$ thick) welded to the steel beam. The tendon eccentricity values, with respect to the centroidal axis of the composite girder were zero at the end sections and 28, 194 at the intermediate support and mid span sections, respectively. A stiffened steel plate $240 \mathrm{~mm}$ in length was welded horizontally to both edges of the bottom flange, extending the supporting length of the beam over the inner support to ensure stability of the structure during
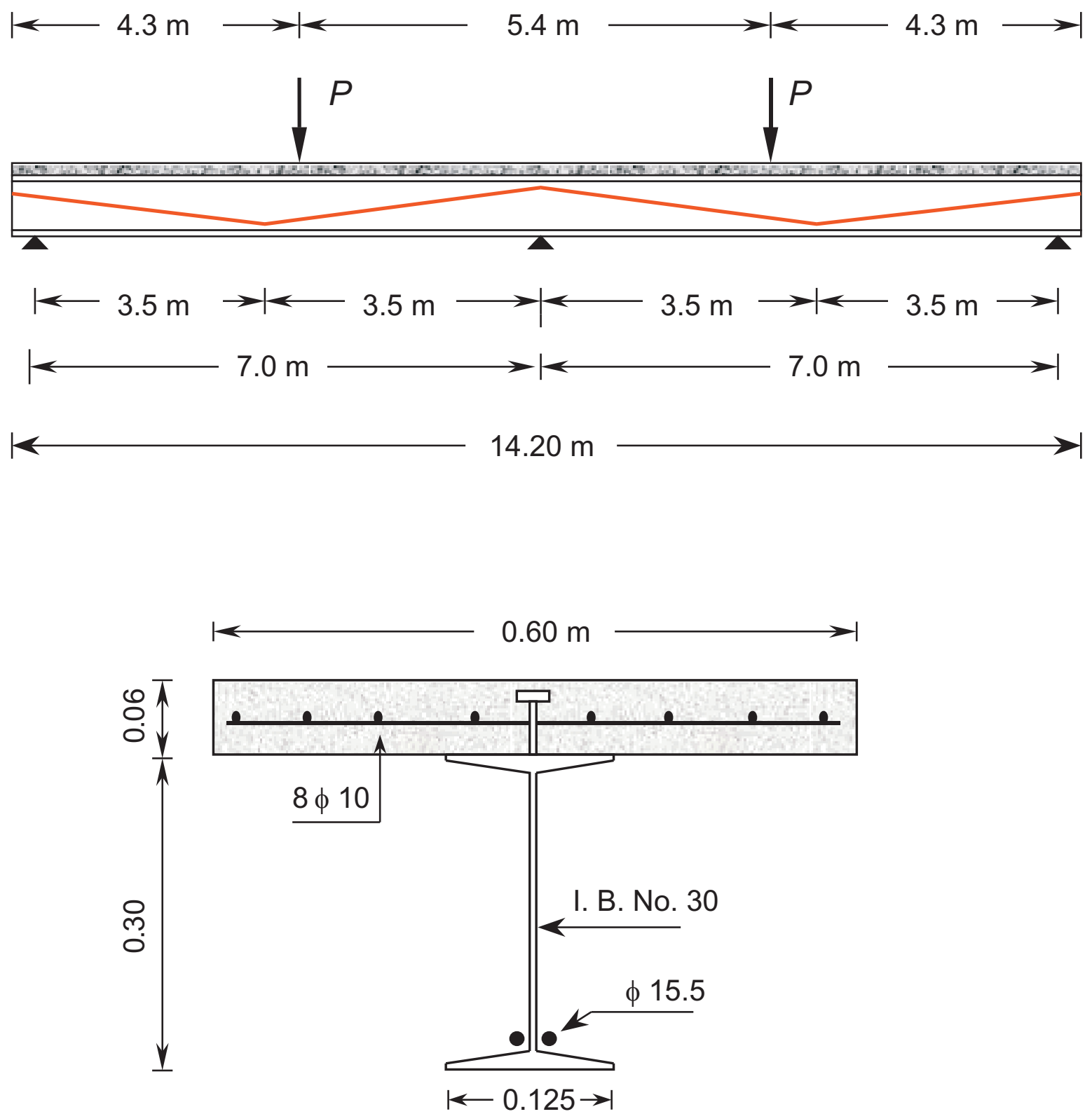

Fig. 1: Loading configuration \& dimensions of the test specimen (Beam B) and cross section at mid-span section 
loading, as shown in Fig. 2. Headed studs were welded to the steel beam top flange in a single row along the web axis. The connectors were symmetrically distributed with respect to the inner support section. Welding of connectors began at the end support sections and towards the inner support at a spacing of $40 \mathrm{~cm}$ over a span length of $3.6 \mathrm{~m}$, after which the spacing was reduced to $20 \mathrm{~cm}$. The studs had a total height of $54 \mathrm{~mm}$ after welding and a shank diameter of $12.6 \mathrm{~mm}$.

The steel beam was positioned over the final supports, and then a wooden form was installed to receive the fresh concrete of the $60 \times 600 \mathrm{~mm}$ slab. A plastic adhesive material was used to fill the narrow gaps between the longitudinal edges of the top flange and the adjacent wooden plate to ensure water tightness of the form. The two horizontal plates forming the soffit of the concrete slab were supported by means of a sufficient number of vertical wooden plates fixed to the longitudinal perlins laid on the floor. Horizontal plates were positioned attached to the soffit of the steel beam that originally received a small portion of the weight of the concrete slab. As a result, the own weight of the steel beam and the concrete slab are taken by the composite beam after stripping of the form. One layer of high tensile steel deformed bars was used to reinforce the concrete slab. The mesh consisted of $8 \phi 10$ mm uniformly distributed longitudinal bars and distributers of the same diameter at a spacing of $20 \mathrm{~cm}$. The mesh was elevated into position by means of plastic blocks $23 \mathrm{~mm}$ in thickness, and thus the centriod of the longitudinal bars can be assumed to coincide with the centriodal axis of the slab. The longitudinal rebars were spliced twice over a length of $70 \mathrm{~cm}$ so that the center of each splice was $2 \mathrm{~m}$ from the adjacent end support.

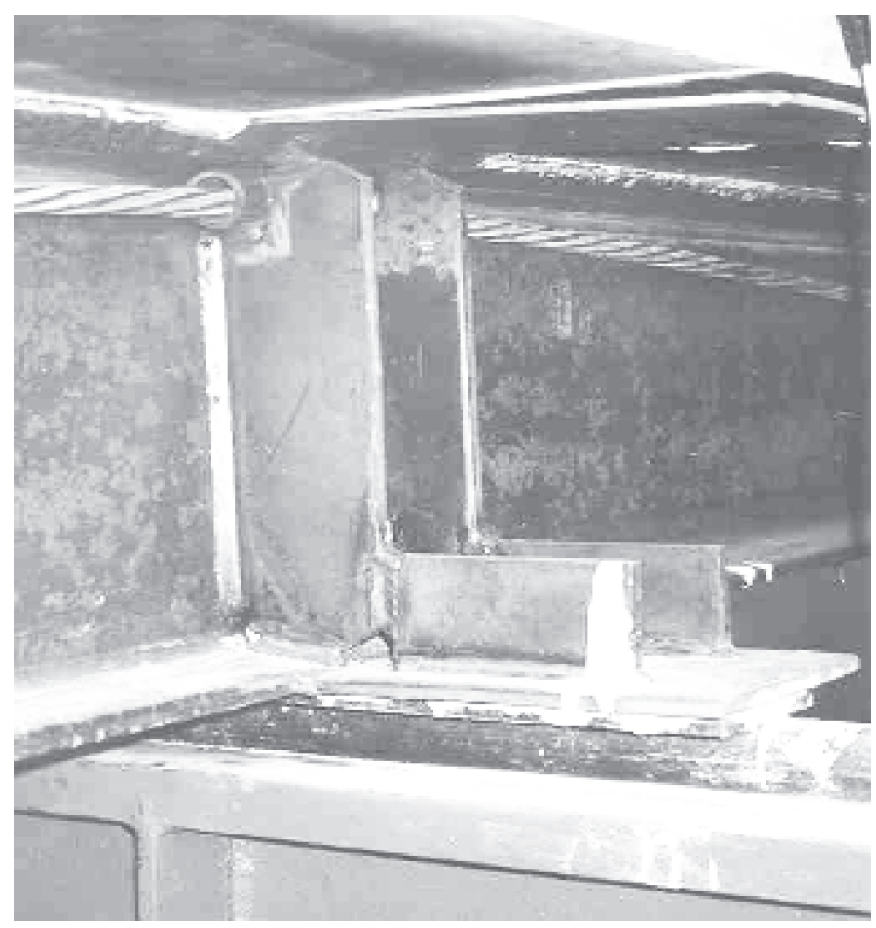

Fig. 2: Structural details at the inner support section

Slab casting: A ready mix self compacting concrete (SCC) patch of $1 \mathrm{~m}^{3}$ was used to cast the slab of the two composite beams and the companion test specimens needed to investigate the different properties of the concrete mix. The concrete was poured from a moving mixing truck directly to the forms. Minimum effort was needed only to level the concrete surface to ensure a constant slab thickness along the beam length. To avoid strength losses, casting of the all specimens was scheduled to take place in no more that 60 minutes from the moment of adding the mixing water. The concrete slabs were kept continuously wet for 7 days, after which the wooden forms were stripped and the slabs were left to dry in the laboratory atmosphere.

Prestressing: Prestressing was applied by means of a $230 \mathrm{KN}$ hydraulic jack connected to an electric pump as a pulling device, Fig. 3. A jacking force of $212 \mathrm{KN}$ was applied to each

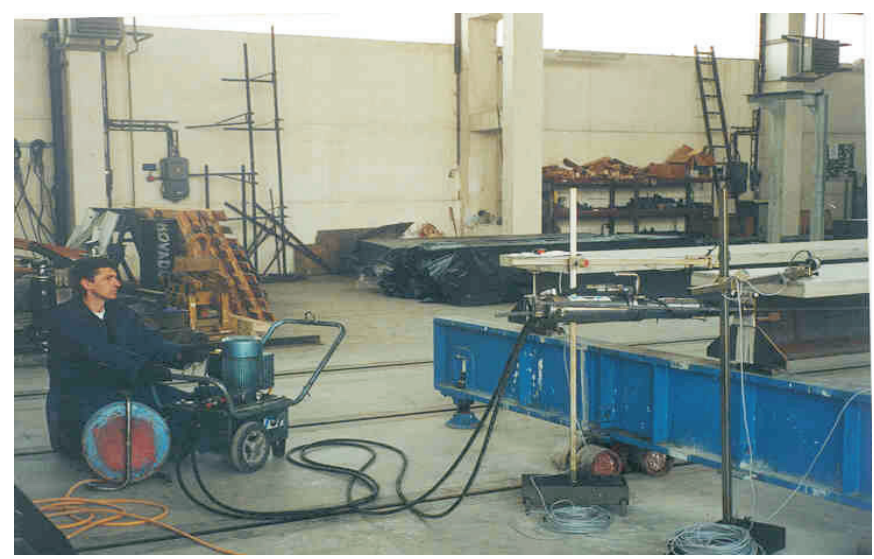

Fig. 3: Stressing of tendons by means of a hydraulic jack unit

tendon inducing a stress of $1497 \mathrm{MPa}$. This value is the maximum stress allowed in Eurocode 4 [9] and represents 90 percent of the yield stress corresponding to $0.1 \%$ permanent strain. The tendons were anchored by means of wedges and anchor chuck grips, as shown in Fig. 4. The tendons were allowed to go through the cylindrical anchor heads installed against the rigid steel diaphragm at the two end support sections. The wedges were then driven to provide sufficient friction, preventing slippage of the tendon towards the beam. About $1 \mathrm{~m}$, length of the tendon was needed to extend behind the anchorage device so as to be clamped inside the movable core of the tensioning hydraulic

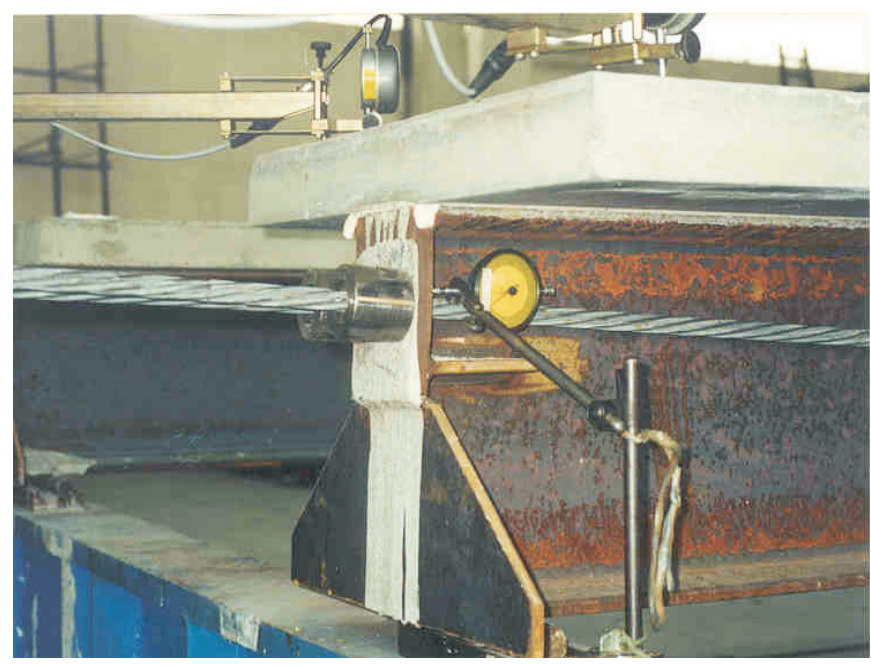

Fig. 4: Structural detail at the end support section showing the head of the anchorage device acting against a rigid steel plate 


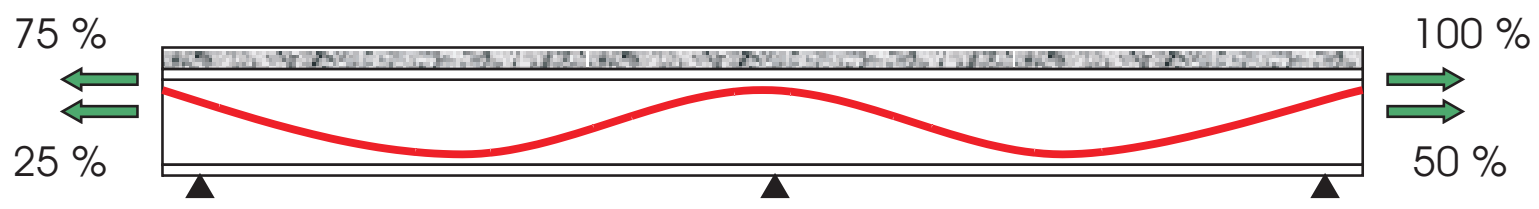

Fig. 5: Application of the tendon stressing force from both sides to uniformly distributed frictional losses along the tendon length

cell. While the tendon was being pulled out, the prestressing cell exerted a reaction against the anchor head and prevented the wedges from moving out, so that the wedges always remained in contact with the tendon during the stressing operation. Upon the release of the jacking pressure, the wedges automatically locked in the conical hole of the anchor head. The tendons were interchangeably stretched at increments of one fourth of the jacking force. Also, each tendon was been stressed from both sides, Fig. 3. Application of the stressing force from both sides, provided that the anchorage system offers such a facility, is recommended so as to avoid the accumulation of frictional losses at the far end segments of the tendon if prestressing were applied from one side. Such a procedure can be more significant if the tendon profile is shaped by means of a big number of saddle points inducing friction losses. However, after the first force increment, a zero reading of the tendon extension was assumed. For each subsequent increment the extension was measured to provide a means of calibrating the applied force based on the tendon standard properties provided by the manufacturer.

\section{Instrumentation and testing of the composite beams}

The instrumentation of the model beams was designed to monitor the load-deflection response intensively along the span. Deflection was monitored by deflection gauges attached to the bottom flange of the steel beam. The applied load was controlled by means of a computerized unit connected to an electric pump. After the gauges were installed, the slab sides were painted in white to facilitate crack detection. Deflection along the two spans of each beam had been measured by means of nine deflection gauges equally distributed along the each span at a spacing of $70 \mathrm{~cm}$ (1/10 of the span length). On the other hand, three sets of deflection gauges were held attached to the top surface of the concrete slab at the end and inner support sections. Each consisted of two units located $5 \mathrm{~cm}$ from the slab edges to make sure that the line joining these two points at the support sections always lay in the same

Table 2: Time schedule for beam testing

\begin{tabular}{|l|c|}
\hline \multicolumn{1}{|c|}{ Operation } & $\begin{array}{c}\text { Time Interval } \\
\text { [days] }\end{array}$ \\
\hline Casting of concrete slabs & 0 \\
\hline Stripping of wooden forms & 7 \\
\hline Prestressing of Beam B & 28 \\
\hline Testing of the prestressed beam & 41 \\
\hline Testing of the nonprestressed beam & 43 \\
\hline
\end{tabular}

horizontal level during all loading stages. Tab. 2 gives a time schedule for testing the model beams.

\subsection{Loading procedure}

The beams were tested under the action of two concentrated simultaneously increasing loads. Each load acted at a distance of $2.7 \mathrm{~m}$ from the inner support. Each load was applied by means of a $600 \mathrm{KN}$ maximum capacity hydraulic jack, which was fitted against the loading frame as shown in Fig. 6. The jacks were driven by an electric pump connected to a computerized unit to control load increment, loading rate, and to maintain a constant value of the acting load during the test. Each point load was applied through a rigid plated steel box, $20 \mathrm{~cm}$ in width, distributing the jacking load uniformly over the slab width. The bearing boxes were laid on a bed of Paris plaster to minimize the effects caused by any unevenness in the underneath slab surface.

Prestressed beam (Beam B): During the first cycle of loading, the load was applied in $20 \mathrm{KN}$ increments at a loading rate of $4 \mathrm{KN} /$ minute. When the load value reached a predetermined value of $150 \mathrm{KN}$ as the beam serviceability load, an unloading process took place at a rate of $90 \mathrm{KN} /$ minute. Because of the distorted dimensions of the test models, it was not convenient to compute the service load value based on the "no cracking" criterion. For this reason, the service load value was determined so as to induce a maximum compressive stress of $200 \mathrm{MPa}$ (0.55 yield stress of the steel beam) at the inner support section. The first cycle was followed by nine cycles in which the beam was loaded from zero to $150 \mathrm{KN}$ in one increment at a loading rate of $45 \mathrm{KN} /$ minute and then reloaded. In the $11^{\text {th }}$ cycle, the load was increased from zero to $150 \mathrm{KN}$ and then in increments of $20 \mathrm{KN}$ at a rate of $4 \mathrm{KN} /$ minute until the maximum was reached. At this final stage of loading, the propagation of yield initiated in the lower part of the steel beam could be recognized by flaking of mill scale that radiated upwards and to the sides about the inner support section.

This observation is in Fig. 7 compared to the same section in Fig. 2 immediately after prestressing. The prescribed criterion could be observed at a load value of $300 \mathrm{KN}$, at which the test was ended. In all stages and after each load increment, the deflection measurements were recorded and the cracking characteristics were carefully observed.

Non-prestressed beam (Beam A): A similar loading procedure to that of beam B was followed. The load was cycled from zero to a predetermined service load value of $110 \mathrm{KN}$ for ten cycles. In the $11^{\text {th }}$ cycle, the load was intended to increase further to a value comparable to that of the prestressed beam. This value was found analytically to be $245 \mathrm{KN}$. However, the test was ended at a load value of $230 \mathrm{KN}$ due to an accidental lateral rotation of the beam, which could be attributed to improper positioning of the applied load. 


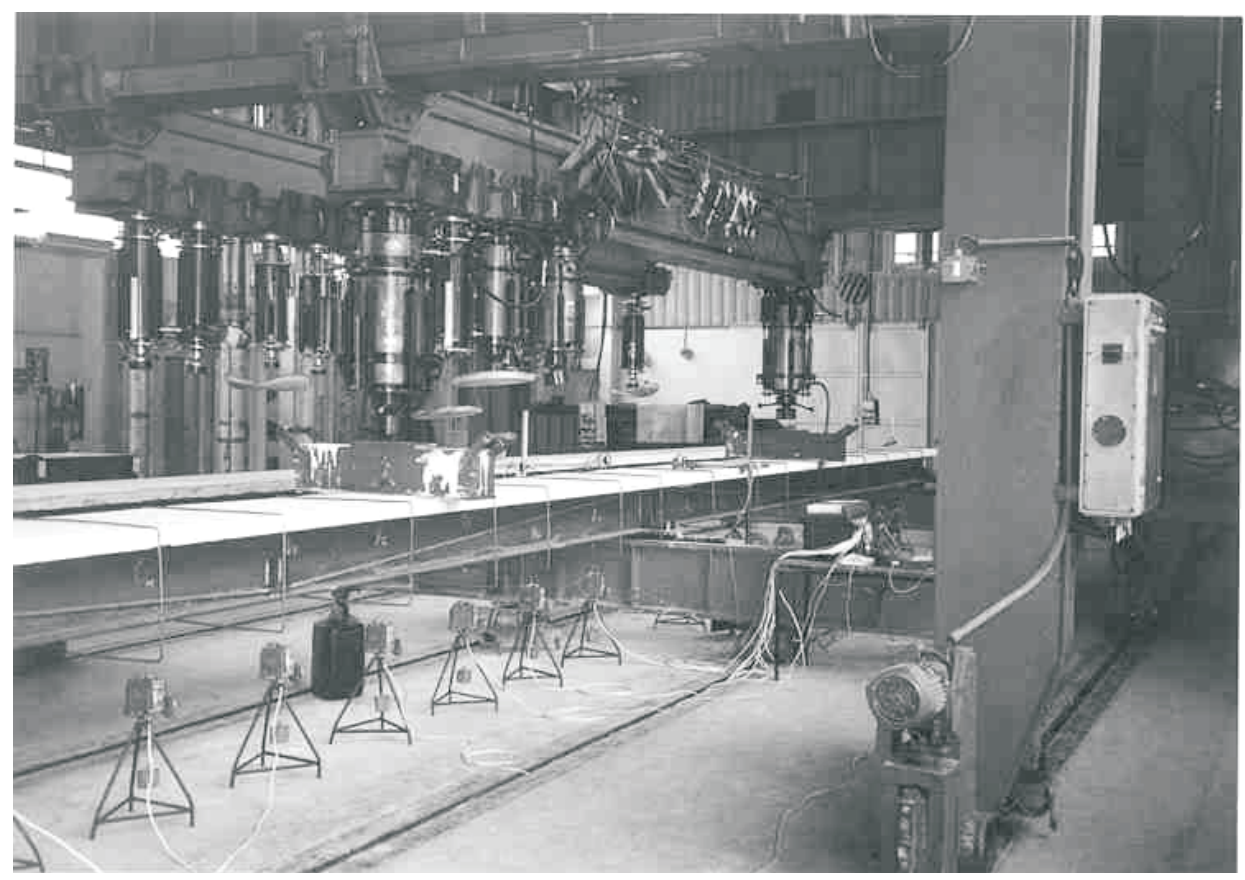

Fig. 6: An overall view of the test specimen and loading frame

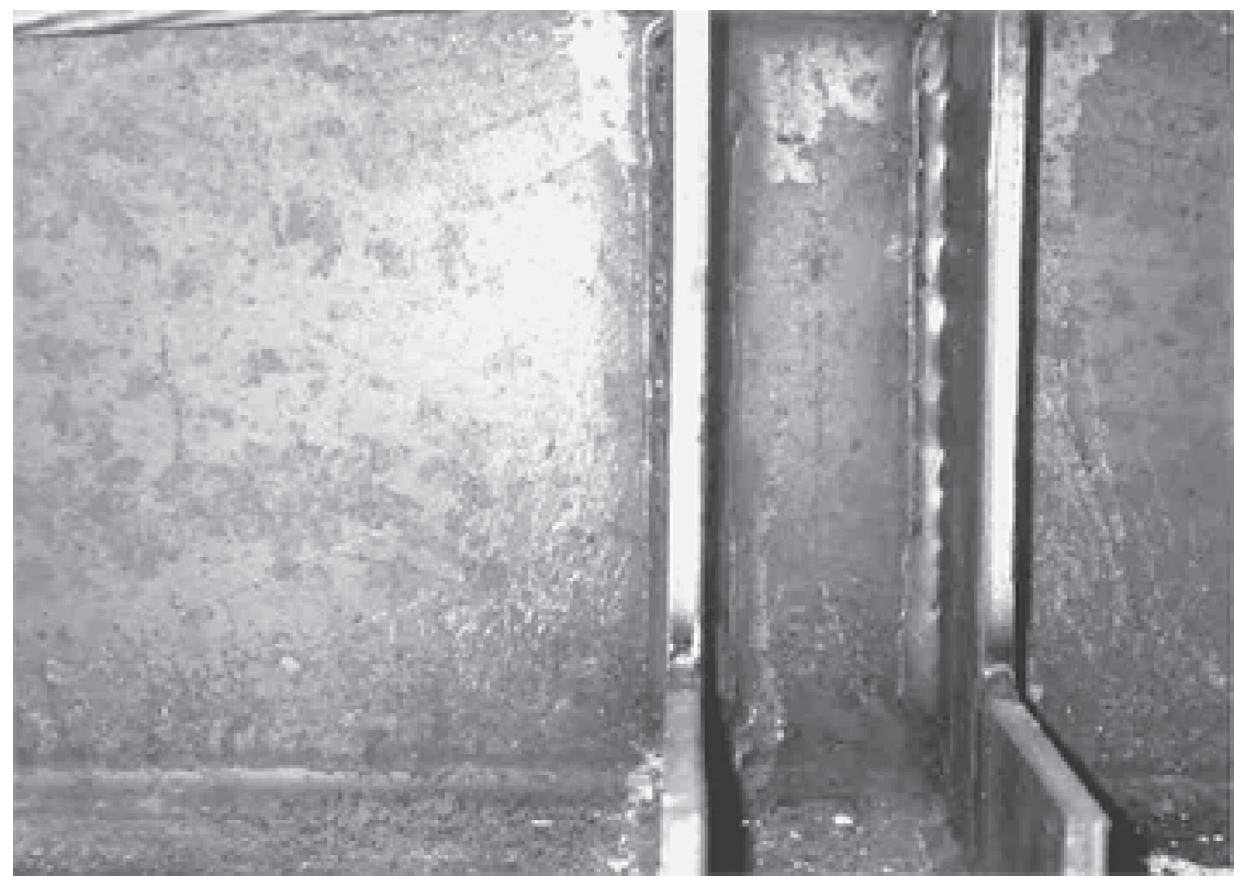

Fig. 7: Diagonal flaking of mill scale indicating the yield development about the inner support section

\section{Discussion of test results}

Fig. 8 shows the load deflection response of the two beams. A stiffer response of Beam B (prestressed) compared to Beam A (non-prestressed) is obvious. The deflection of Beam A at service load (110 KN) was 1.87 times higher than the corresponding value in case of Beam B at the same load value. The first yield in Beam A occurred in the extreme fiber of the lower flange at the inner support section at a load of $190 \mathrm{KN}$. At this stage the above deflection ratio reduced to 1.4 as the deflection increased in both beams, while a slight non-linear effect appeared due to deck cracking. However, by the end of testing of Beam A, the deflection ratio increased to 1.75 , demonstrating the obvious non-linear response of Beam A compared to Beam B up to the same loading level. The figure also shows that the deflection was nearly the same in both beams at the end of testing, although the load carried by Beam B was 30 percent higher. The almost parallel load-deflection curves of the two beams up to the yield load of Beam A, demonstrate that the stiffer response of Beam B refers mainly to cambering associated with beam prestressing.

The load carrying capacity of the tested beams at different loading stages is shown in Fig. 9. It can be seen that an improvement in the mechanical behaviour in terms of load car- 


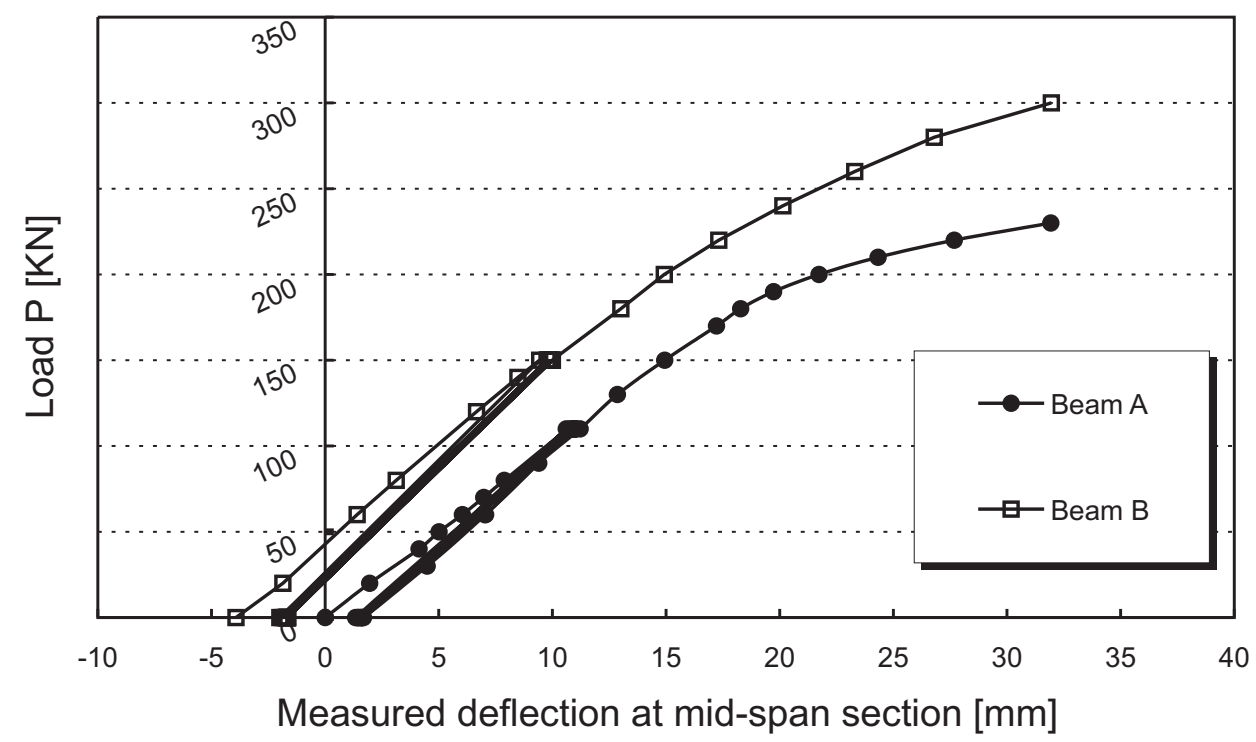

Fig. 8: Load-deflection response for Beam B (prestressed) \& beam A (non-prestressed)

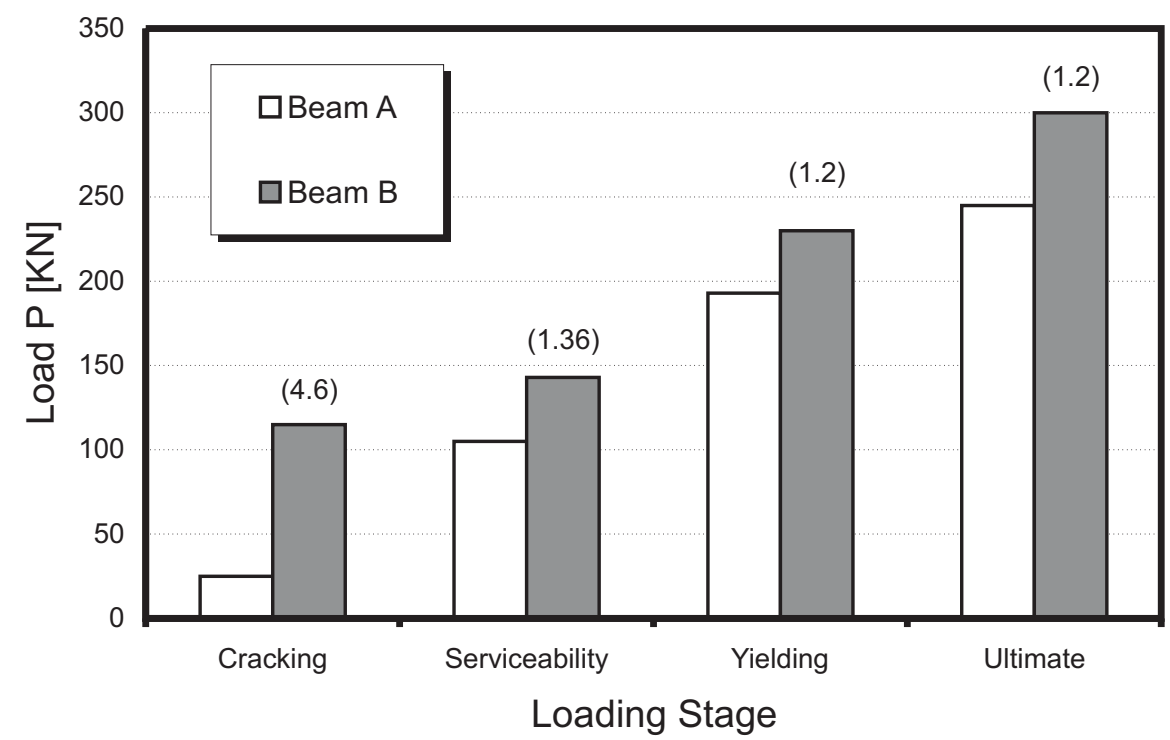

Fig. 9: Load carrying capacity at different stages of loading

rying capacity was achieved thanks to prestressing. Cracking, serviceability, and ultimate loads were $4.6,1.2$, and 1.2 times higher in Beam B compared to Beam A, respectively. Obviously, the remarkable delay of crack initiation is a highly desired feature for serviceability performance.

Other cracking characteristics are demonstrated in Figs. 10, 11. At service load, the total number of cracks devel- oped in Beam A was 23 spreading over 14 percent of the beam length. In Beam B the corresponding number of cracks was only 7 over 4 percent of the beam length. By the end of testing, the number of cracks in Beam A increased to 31 spreading over 17 percent of the beam length. The corresponding values in beam B were 20 and 9 percent, respectively. In Beam A, the cracking width was limited to $0.1 \mathrm{~mm}$

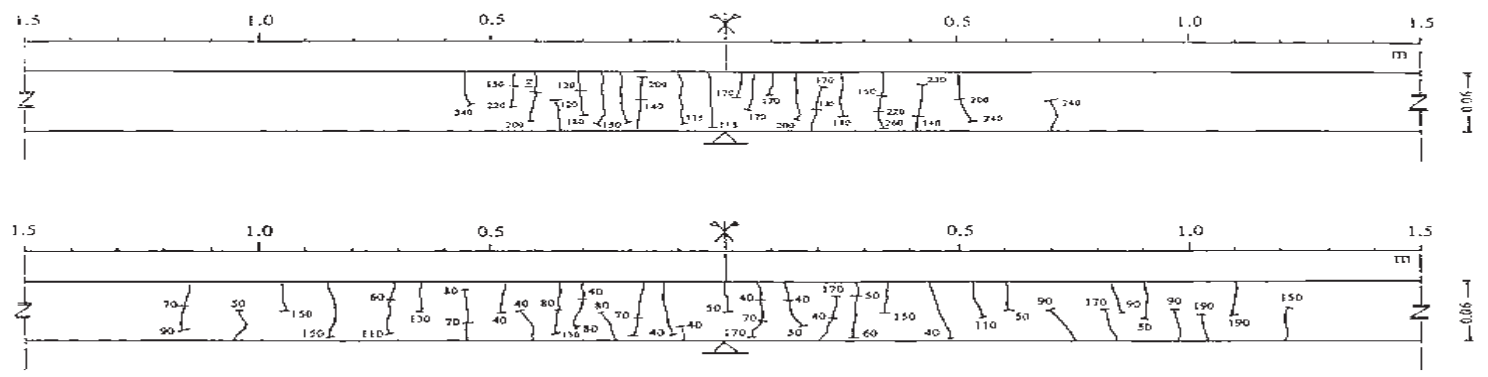

Fig. 10: Cracking pattern 


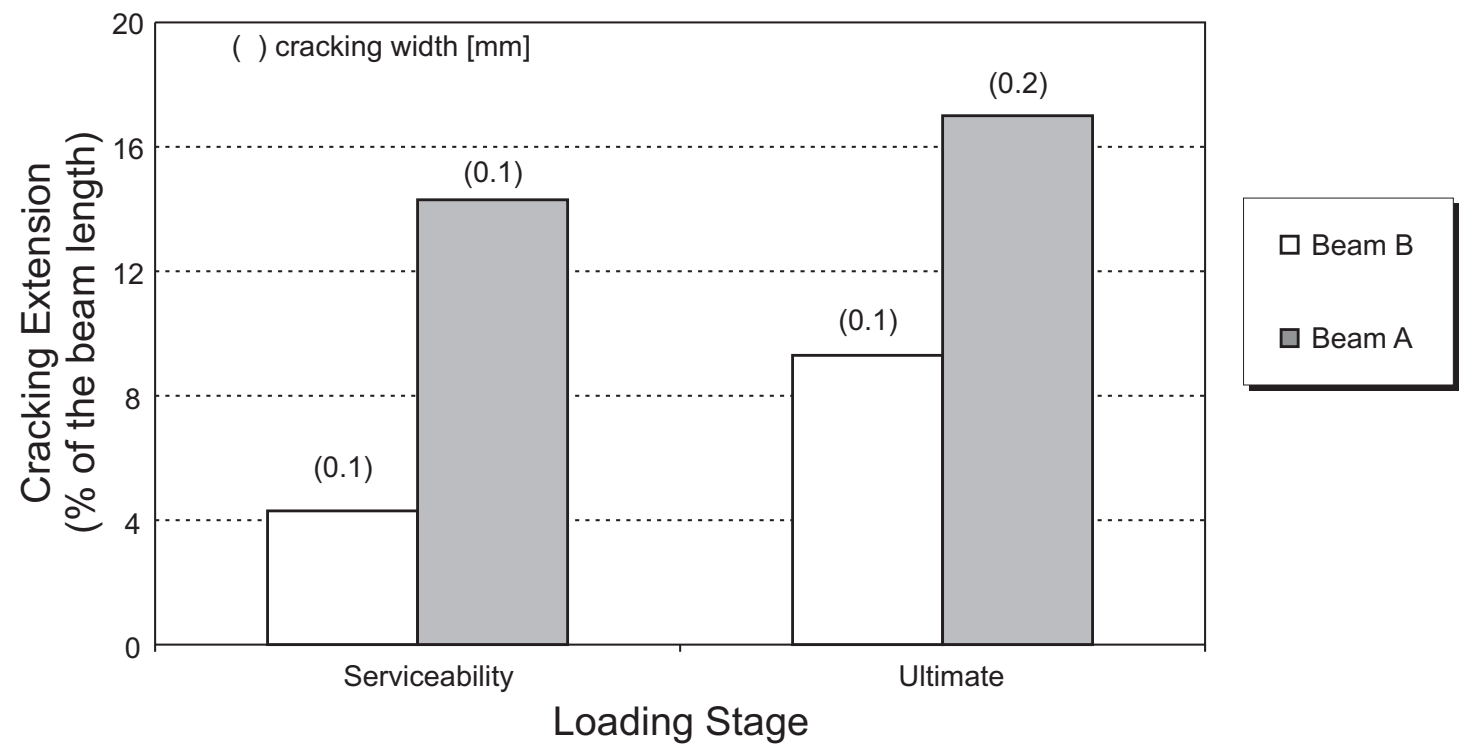

Fig. 11: Cracking extension and cracking width at different loading stages

due to the relatively high reinforcement ratio of 1.75 percent. However, the cracking width further increased to $0.2 \mathrm{~mm}$ by the end of loading. Thanks to prestressing, the cracking width was limited to $0.1 \mathrm{~mm}$ at all loading stages.

\section{Conclusions}

The experimental work conducted in the current research demonstrates that external prestressing is relatively easy to apply provided that proper dimensional details are designed. The application of prestressing improved the mechanical performance remarkably giving the following results:

1. While Beam A first cracked at a load of $25 \mathrm{KN}$ the corresponding load for Beam B was 4.6 times higher (115 KN).

2. By the end of testing, the total number of cracks in Beam A was 31 spreading over a length of $233 \mathrm{~cm}(16.6 \%$ of the structure length). The number of corresponding cracks in Beam B was limited to 20 cracks over a length representing only $9 \%$ of the beam length.

3. During all loading stages in Beam B, a maximum crack width of $0.1 \mathrm{~mm}$ was recorded. An equal cracking width was measured in Beam A at the initial stages of loading at the serviceability level. However, this value further increased to $0.2 \mathrm{~mm}$ at the end of testing.

4. The loading capacity in terms of plastification of steel at the inner support section corresponded to a load of $300 \mathrm{KN}$ in Beam B, which was 30 percent higher than that for Beam A (230 KN).

5. The application of a relatively high slab reinforcing ratio $(1.75 \%)$ made it possible to limit cracking width to $0.1 \mathrm{~mm}$ at service load in the non-prestressed beam. However, cracks became wider at higher load levels.

6 . The load - deflection response indicated a remarkable increase in stiffness due to prestressing. The deflection of the non-prestressed beam was $1.87,1.4$, and 1.75 times higher than that of the prestressed beam at service, yield, and ultimate load values of the non-prestressed beam, respectively.

7. The almost parallel load-deflection curves up to the yield load of the non-prestressed beam demonstrate that reduced deflections refer mainly to cambering associated with external prestressing.

\section{References}

[1] Dall'Asta, A., Dezi, L.: Construction sequence effects on externally prestressed composite girders. International Conference Report: Composite construction: conventional and innovative. Innsbruck - Austria, September 16-18, 1997, pp. 301-306

[2] Viest, I. M., Colaco, J. P., Furlong, R. W., Griffis, L. G., Leon, R. T., Wyllie, L. A.: Composite construction design for buildings. Co-published by McGraw Hill \& American Society of Civil Engineers (ASCE), 345 East $47^{\text {th }}$ Street, New York, 1997, NY 10017-2398, ISBN 0-07-067457-4

[3] Commission of the European Communities: Design of composite steel and concrete structures. Eurocode 4, 1992

[4] AISC: Manual of steel construction, LFRD. $1^{\text {st }}$ edition, American Institute of Steel Construction (AISC), Chicago, 1987

[5] Gilbert, R. I., Bradford, M. A.: Time-dependent behavior of continuous composite beams at service loads. Journal of Structural Engineering, Vol. 121, No. 2/1995, pp. 319-327

[6] Dezi, L., Leoni, G.: Time-dependent behavior of continuous composite beams: comparison among different prestressing techniques. Costruzioni Metalliche, April 1997, No. 2, pp. 15-27

[7] Dezi, L., Tarantino, A. M.: Creep in composite continuous beams I: theoretical treatment. Journal of Structure Engineering, ASCE, Vol. 119, No. 7/1993, pp. 2095-2111 
[8] Amadio, C., Fragiacomo, M.: A finite element method for the study of creep and shrinkage effects in composite beams with deformable shear connection. Costruzioni Metalliche, No. 4/1993, pp. 213-228

[9] Tong, W., Saadatmanesh, H.: Parametric study of continuous composite girders. Journal of Structural Engineering, ASCE, Vol. 118, No. 1/1992, pp. 186-205

The support provided for this research by the Grant Agency of the Czech Republic, Project No. 103/99/0734 is gratefully acknowledged.
Eng. Mohamed Safan, MSc

phone: +420224354620

e-mail:msafan@beton.fsv.cvut.cz

Ing. Alena Kohoutková, CSc.

phone: +420224353740

e-mail: akohout@fsv.cvut.cz

Dept. of Concrete Structures and Bridges

Czech Technical University in Prague

Faculty of Civil Engineering

Thákurova 7, 16629 Praha 6, Czech Republic 